\title{
PEGADA ECOLÓGICA ADAPTADA: PASSOS PARA UM FUTURO MELHOR
}

Luciana Cogliatti de Carvalho ${ }^{1}$

Resumo: A reflexão sobre a nossa relação com o planeta encontra espaço nas escolas apenas em aulas específicas, e não tem alcance o suficiente para explicar como chegamos ao atual modelo de extração de recursos e ao cenário de crise ecológica que encontramos hoje. Esse estudo tem por finalidade apresentar aos alunos do Ensino Fundamental e Médio o conceito da pegada ecológica e assim propor um debate sobre os impactos causados pela nossa demanda por diversos produtos, tentando mostrar que somos a outra ponta de uma cadeia que começa nas grandes indústrias. Ao mesmo tempo o trabalho tenta levar os alunos a reproduzir esse debate, aplicando a pegada no ambiente intra e extraescolar e extrapolando a reflexão sobre os impactos que o nosso dia-a-dia causa no planeta, com um enfoque no momento póspandemia.

Palavras-chave: Educação Ambiental; Pegada Ecológica; Interdisciplinaridade; Questionário; Pandemia.

Abstract: The reflexion on our relationship with the planet is found in schools only in specific classes, and it is not able to explain how we have the current model of resource extraction and the scenario of current ecological crisis. This study aims to introduce the concept of ecological footprint to elementary and high school students and, therefore, propose a debate on the impacts caused by the demand for different products, trying to show that we are the opposite side of a chain that starts in large industries. At the same time, this work tries to get students to think about this debate, applying an in and out-of-school environment and extrapolating a reflection on the impacts that our daily lives cause on the planet, with a focus on the post-pandemic moment.

Keywords: Environmental Education; Ecological Footprint; Interdisciplinarity; Questionnaire; Pandemic. 


\section{Introdução}

O uso indiscriminado dos recursos ambientais e a poluição provocada pelas formas de extração e uso dos mesmos vêm causando impactos visíveis em diversos locais ao redor do planeta. Para HEINBERG (2007), a humanidade já atingiu um ponto em que usamos mais recursos do que a Terra pode renovar. Isso tem levado pesquisadores, ao longo dos últimos anos, a determinar o quanto de recursos nós devemos extrair para que possamos utilizar a "natureza" de forma que as futuras gerações não tenham a sua sobrevivência comprometida. Assim, a partir desse contexto, como, então, podemos chamar a atenção para essas questões? Como, em meio a tantos discursos de proteção ao meio ambiente e de denúncias e ameaças à vida, podemos criar algo que realmente nos faça parar? Como podemos fazer para identificar no nosso cotidiano a nossa contribuição, a nossa participação nesse processo? E o que considerar agora, em tempos de isolamento social e pandemia?

No que diz respeito à escola precisamos observar que essa é uma questão a ser olhada por muitos ângulos e disciplinas, a fim de desenvolver nos estudantes uma consciência ambiental de forma a garantir os recursos naturais para as futuras gerações (SOUZA, 2020). Falar sobre meio ambiente, ecologia, sobre natureza, sobre sustentabilidade, sobre consumo e produção é adentrar num campo que coloca um desafio que deve ser tratado de forma multidisciplinar (OLIVEIRA; NEIMAN, 2020).

A Pegada Ecológica original é um conceito apresentado em 1996 pelos pesquisadores William Rees (canadense) e Mathis Wackernagel (suíço) no livro "Pegada Ecológica - reduzindo o impacto do ser humano na Terra", que consiste em um questionário com perguntas e opções de respostas referentes aos nossos hábitos cotidianos e, ao final, é calculado quantos planetas Terra são necessários para sustentar o nosso estilo de vida ${ }^{2}$. Com essa nova ferramenta tornou-se possível mostrar às pessoas o quão lesivo ao planeta podem ser suas práticas do dia-a-dia, tornando-se uma forma muito importante para demonstrar a importância de se rever o nosso consumo e como nos relacionamos com o planeta. Essa ferramenta traz consigo a ideia de espaço necessário para manter cada um de nós e nosso estilo de vida, tendo a unidade de hectares globais como medida básica, o que torna mais palpável os resultados obtidos por esse teste. Tomando como base as questões presentes na Pegada Ecológica original ${ }^{3}$, conclui-se que ela se destina predominantemente a pessoas com maior poder aquisitivo, tendo como base cidadãos de países desenvolvidos, em sua maioria do hemisfério norte, o que Ihes permite, por exemplo, fazer viagens constantes de avião. No entanto, para aplicar adequadamente a Pegada Ecológica aos alunos das escolas públicas brasileiras, optamos por adaptar questões às quais os alunos se identificassem

\footnotetext{
$2<$ https://www.wwf.org.br/natureza brasileira/especiais/pegada ecologica/historico/>

${ }^{3}$ Encontrada no site <http://www.footprintnetwork.org/en/index.php/GFN/page/calculators/>
} 
e que melhor representassem a sua realidade. Desta forma, reformulamos o questionário original e criamos a Pegada Ecológica Adaptada, mantendo o mesmo tema central que consiste no impacto causado no ambiente resultante de ações cotidianas, o que inclui questões referentes ao tipo de moradia, destinação de lixo, consumo de carne vermelha, uso de transportes e de energia e consumo de eletrônicos.

\section{Objetivo Geral}

O presente trabalho tem por objetivo gerar uma estratégia didática desenvolvida e adaptada à escola, e extensiva ao ambiente extraescolar, através do questionário Pegada Ecológica Adaptada, que permite aos alunos avaliar de que modo suas atividades cotidianas podem interferir e deixar "rastros" no Planeta, e propor uma visão crítica do momento de isolamento social e pandemia que estamos vivenciando. Assim, através dessa ação, incentiva-se a pesquisa, a investigação, a conscientização e o debate com o grupo envolvido no trabalho dos dados coletados.

\section{Objetivos Específicos}

- Incentivar o senso crítico nos alunos;

- Promover debates sobre o tema das relações do ser humano com o meio ambiente;

- Possibilitar outra fonte de debates ecológicos na escola, de forma que os alunos se sintam mais conectados.

- Gerar uma interface entre as diversas disciplinas que abordem o assunto.

\section{Metodologia}

A atividade do questionário foi realizada no Colégio Estadual Cizinio Soares Pinto, com professores, gestores, funcionários e nas turmas do Ensino Fundamental e Ensino Médio. Nas turmas são trabalhados temas sobre uso de energia, cidadania, aspectos históricos e culturais de consumo, Educação Ambiental e Ecologia, possibilitando a utilização da Pegada Ecológica Adaptada dentro de um contexto interdisciplinar em sala de aula e como nosso ponto de partida para trabalhar estes temas.

A $3^{a}$ série do ensino Médio é responsável por aplicar o questionário em todas as turmas da escola e seus professores, no turno da manhã (Figura 1). No turno da tarde, os professores são os responsáveis por selecionar os alunos que irão aplicar o questionário nas turmas neste turno, assim como a professores e funcionários. 


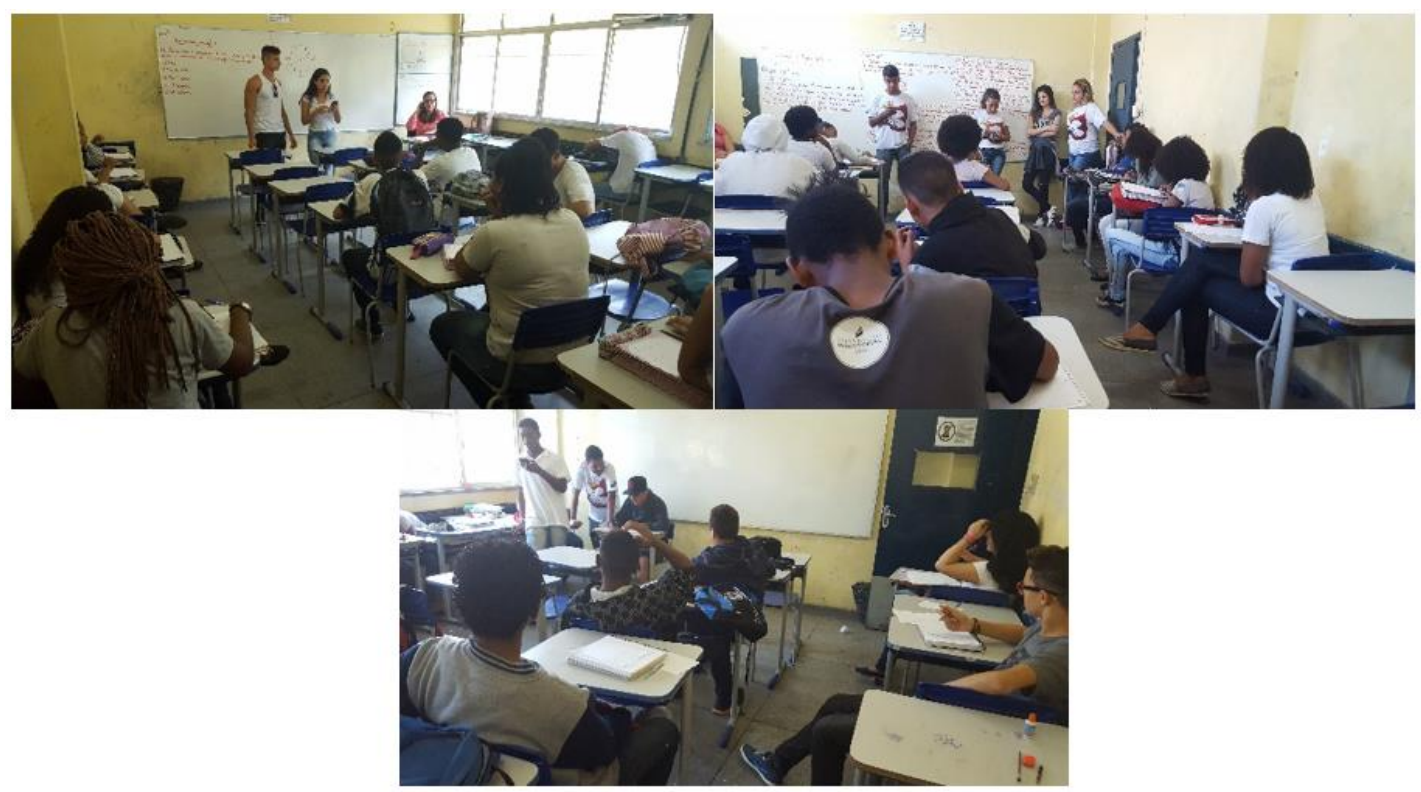

Figura 1: Alunos da 3aㅗ série do ensino médio do Colégio Estadual Cizínio Soares Pinto aplicando o questionário Pegada Ecológica Adaptada a toda a comunidade escolar.

A estrutura do questionário foi assim definida:

$1^{\text {a }}$ parte: Foram elencadas 20 perguntas com cinco opções cada de $A$ à $E$, com respectivo valor de 1 à 5 pontos.

2 ${ }^{\mathbf{a}}$ parte: Foi agregado à pontuação um valor ecológico sendo 1 sempre o menos impactante para o meio ambiente e, de modo crescente, 2, 3, 4 e 5 opções mais impactantes ao meio ambiente.

3 parte: Foi estabelecido um ranking com três categorias, de acordo com a pontuação obtida no somatório dos pontos das respostas:

De 20 a 46 pontos: Parabéns! Continue assim, pois seu impacto no ambiente é bem pequeno!

De 47 a 73 pontos: Cuidado! Se não repensar seu cotidiano seu impacto no meio ambiente pode aumentar cada vez mais.

De 74 a 100 pontos: Pare! Com esse comportamento não há Terra que aguente!

No Apêndice I estão as questões e opções de respostas da Pegada Ecológica Adaptada aplicadas no Colégio Estadual Cizínio Soares Pinto, em Niterói, RJ.

Após a aplicação do questionário, cada indivíduo faz o somatório dos seus resultados e verifica a pontuação final.

De acordo com o ranking descrito acima, o indivíduo recebe uma lembrança, confeccionada pelos alunos da $3^{3}$ série do ensino médio, condizente com o seu resultado (Figura 2): 
- "Parabéns": carinha verde sorrindo se seu resultado for satisfatório, com impacto mínimo;

- "Cuidado": carinha laranja sem sorrir se seu resultado for de atenção, com impacto médio;

- "Pare!": carinha vermelha triste se seu resultado for altamente impactante.

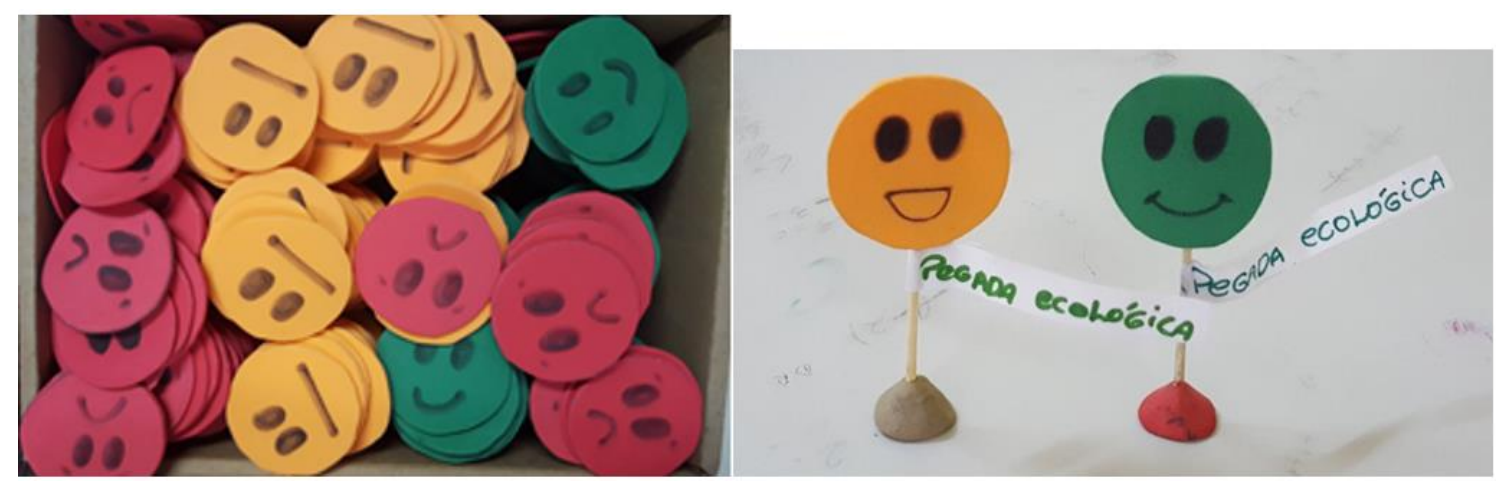

Figura 2: Brindes de "carinha" confeccionados pelos alunos da $3^{\mathrm{a}}$ série do ensino médio, condizente com o seu resultado no questionário Pegada Ecológica Adaptada, no Colégio Estadual Cizínio Soares Pinto, em Niterói, RJ.

Segundo OLIVEIRA e AMARAL (2020), é essencial que o corpo docente perceba a importância da prática pedagógica na Educação Ambiental e a sua possibilidade de transpassar por todas as disciplinas. Todos os professores das diversas disciplinas envolvidas com o Projeto, direta ou indiretamente, desenvolvem atividades referentes à sua matéria, como sugestões:

- Artes - confecção de painéis e cartazes informativos sobre sustentabilidade, meio ambiente e sobre a Pegada Ecológica do Cizínio;

- Biologia e Geografia - conceitos de Ecologia, meio ambiente, diversidade de espécies, biomas, cadeia alimentar e ciclos biogeoquímicos;

- Filosofia e Sociologia - discussões sobre cidadania, consumismo, valores, ética e sobre o papel do cidadão na preservação do ambiente;

- História e Filosofia - discussão sobre o consumo dos recursos naturais em diferentes épocas da história da humanidade;

- Matemática - construção de gráficos demonstrando os resultados por turma e do total da comunidade escolar, números inteiros e porcentagem;

- Português - leitura e interpretação de textos referentes ao assunto.

Além dessas, outras atividades e abordagens podem ser trabalhadas nas diversas disciplinas, aderindo e contribuindo com o Projeto, de acordo com o interesse e disponibilidade do professor. 


\section{Resultados e Conclusões}

\section{Pegada Ecológica Adaptada}

Espera-se, com este trabalho, conscientizar os indivíduos e convidá-los a rever algumas respostas e, em autoanálise, identificar em quais pontos devem repensar atitudes e mudar os hábitos para contribuir com a redução da própria Pegada Ecológica e, consequentemente, do impacto ao meio ambiente.

Somado a isto, espera-se criar uma forma de aproximar o discurso ambiental para um nível onde cada indivíduo perceba a sua parcela de participação no problema e, assim, na solução do mesmo, numa tentativa de validar esses discursos que já estão ficando, de certa forma, esvaziados de sentido. Assim, tentamos trazer para a sala de aula outra possibilidade de entrar nesse campo de discussão, lançando mão de uma ferramenta, embora nada inédita ou nova, mas ainda pouco utilizada nas escolas no trabalho de discussão sobre a questão ambiental. Tal ferramenta foi a Pegada Ecológica (Adaptada).

Os resultados desta Pegada Ecológica Adaptada foram apresentados no auditório do Colégio Estadual Cizínio Soares Pinto a alunos e professores convidados de outra escola vizinha da região, o Colégio Brasil-França, localizado em Charitas, Niterói. Este evento foi uma oportunidade de intercâmbio e interação entre alunos e professores de diferentes escolas, e foi lançada a proposta aos alunos da escola convidada a também calcularem a Pegada Ecológica do Brasil-França. Esta prática funcionou como disseminadora da proposta de Educação Ambiental, gerando uma conscientização geral acerca das discussões ambientais.

Questões referentes à geração de lixo, consumo direto e indireto de recursos naturais e respeito às demais espécies de seres vivos são contempladas neste trabalho, levando aos estudantes a percepção de quanto suas atitudes diárias afetam o meio ambiente. O maior desafio é criar condições para que as iniciativas educacionais sejam estratégicas para realizar as mudanças necessárias para motivar os cidadãos a agir em direção às metas de sustentabilidade (JACOBI et al., 2011). Percebe-se o quanto as políticas públicas podem interferir minimizando esta interferência no ambiente, através de, por exemplo, programas de Educação Ambiental e de coleta seletiva de lixo reciclável nas comunidades. Constata-se, desta forma, o quanto a Educação Ambiental é imprescindível na valorização de todas as espécies viventes no planeta, inclusive a humana, e na manutenção da preservação do ambiente e do seu uso sustentável.

\section{Discussão no contexto atual de pandemia, e soluções para o futuro próximo}

$\mathrm{Na}$ Educação Ambiental, aprendemos que todo e qualquer ser vivo sobre a face da Terra tem a sua significância, e não menos importantes são os vírus e o seu papel no processo evolutivo das espécies (ARNEY, 2020). Não

revista brasileira educação ambiental 
podemos negar que, como parte integrante do meio ambiente, o ser humano interfere diretamente nele, e sofre as consequências desta interferência (PESSANHA; RODRIGUES; ALVES, 2016). As zoonoses, em particular, são o resultado da interação do ser humano com os animais, que atuam como vetores de diversas doenças (PIGNATTI, 2003), incluindo o SARS-COV-2, vírus causador do COVID-19.

A atual pandemia por corona vírus fez com que o mundo parasse. Mudase os hábitos, reduz-se o consumo, principalmente de supérfluos, e mantémse, na medida do possível, o consumo de insumos essenciais básicos. É, portanto, inevitável que a atividade industrial seja reduzida, e isto acarreta consequências para todo o mundo. Tem sido constatada a redução da poluição atmosférica, principalmente por dióxido de nitrogênio $\left(\mathrm{NO}_{2}\right)$ e dióxido de carbono $\left(\mathrm{CO}_{2}\right)$, em diferentes locais do mundo, incluindo Nova lorque e China (UFJF, 2020). Segundo SOUSA (2020), esta pausa no mundo, ocasionada pela pandemia, confere a educadores ambientais, cientistas e cidadãos com pensamento crítico reflexivo a esperança de mudanças no comportamento social, político, econômico e ambiental, culminando com o tão sonhado Desenvolvimento Sustentável.

Como plano de ação pós-isolamento, devemos incluir ações práticas para preservar ou reduzir o impacto no ambiente - já que zero impacto não é possível - e nos relacionar de forma pacífica e sustentável com a natureza. Estudos científicos demonstram que a interação dos humanos com a natureza faz bem à saúde física e mental, reduzindo o estresse, a pressão sanguínea e o risco de infecções (MCDONALD; BEATLEY; ELMQVIST, 2018). A redução no consumo de carnes, de eletrônicos, de bens materiais supérfluos e de plástico; o desapego e o descarte correto de produtos não mais utilizados; o reaproveitamento de água da chuva, e a coleta seletiva de lixo reciclável são ações práticas que podem contribuir para a redução do impacto ao meio ambiente. A manutenção da qualidade de saúde e vida humana condiz com questões relacionadas à consciência ecológica e conservação ambiental (FONSECA, 2012). Alguns pesquisadores acreditam, no entanto, que a desaceleração no ritmo de produção e consumo é temporária, e voltará a causar os mesmos danos à natureza após cessar o estado de pandemia, com exceção de uma pequena parte da população a qual detém uma maior consciência ambiental (UFJF, 2020).

Neste contexto mais atualizado em que estamos vivenciando, considerando o isolamento social durante a pandemia do COVID-19, algumas questões são necessárias de serem respondidas. Uma delas diz respeito às atividades agora suspensas, que poderiam não ser retomadas, como a utilização demasiada de papéis nas escolas. As escolas estão adotando o ensino remoto pela internet, e muitas utilizam plataformas virtuais de ensino, como forma de manterem as atividades escolares. Em termos de didática e práticas pedagógicas, podemos e devemos manter estes novos hábitos e estratégias após a pandemia. Se o uso da tecnologia era importante antes da pandemia, sua aplicação se torna indispensável nos novos tempos que virão. 
A utilização de atividades escolares através da tecnologia digital vem reduzindo o uso do papel, de equipamentos para impressão (como a tinta e a própria impressora) e a geração de lixo e, assim, contribui para a sustentabilidade e manutenção das futuras gerações.

Por outro lado, que atividades deveriam ser retomadas, e que agora estão suspensas? Considero o retorno do ensino presencial muito importante como atividade a ser retomada após o fim da pandemia, com alguns cuidados dentro de uma nova realidade. A escolarização é essencial para o desenvolvimento social dos jovens, e primordial para a evolução do indivíduo como cidadão (LEITE, 1989), que interage com uma ampla gama de pessoas, ideias e pensamentos. O convívio social desenvolve o respeito às diferenças, o aprendizado perante as decepções, o pensamento crítico, a autonomia, o autoconhecimento e diversos outros sentimentos (DESSEN; POLONIA, 2007), enfim, desperta a resiliência do indivíduo. Novos hábitos deverão surgir após a pandemia no ambiente escolar, como o hábito de lavar as mãos com mais frequência e manter as salas ventiladas, de forma que ações práticas de higiene prevaleçam entre o convívio escolar.

Outra questão, que é também muito importante considerar, seria o "novo normal". Como construir sociedades sustentáveis aproveitando a oportunidade que a crise climática e de saúde mundial nos proporciona? Médicos cardiologistas ressaltam que os seres humanos, de maneira geral, não nasceram para viverem isolados socialmente, e o isolamento pode levar a um aumento de casos de ansiedade e depressão (RODRIGUES, 2018), principalmente entre os jovens de 14 a 20 anos (MAIA; DIAS, 2020). Desta forma, o "novo normal" não consiste em vivermos isolados socialmente, mas sim em mantermos um afastamento físico, evitando aglomerações; e atenção às práticas de higiene, uma vez que, enquanto não é produzida uma vacina, o vírus COV-2 permanecerá por um tempo significativo entre a população. Assim, o "novo normal" nos permite mantermos relações virtuais de trabalho e de lazer, utilizando a internet, aplicativos de reuniões virtuais e redes sociais. Tal prática pode levar a uma diminuição no consumo de recursos, como gastos com alimentação em restaurantes, vestimentas e transporte, reduzindo a Pegada Ecológica dos cidadãos. Em contrapartida, o tempo utilizado frente à tela de computadores e celulares aumenta, resultando em maior gasto de energia nos lares. Seria interessante refazer o questionário da Pegada Ecológica Adaptada nos momentos durante e após a pandemia, e identificar em quais pontos nossa pontuação passou por mudanças, revendo a interpretação dos resultados.

O mundo não existe apenas para nós, humanos. Nós, humanos, estamos aqui graças ao mundo. Somos resultado de um processo evolutivo ocorrido há milhares de anos, que nos permitiu existir. A solução está, ao meu ver, resumida em uma palavra: SERENIDADE. Que sejamos mais serenos na velocidade das ações, no consumo, na geração de lixo, na vida, na nossa Pegada Ecológica! Que tipo de 'ser' queremos ser agora, e depois que o isolamento acabar? 
Este trabalho possui potencial para criar um debate não apenas entre os alunos das escolas, mas também com a comunidade onde os mesmos vivem, considerando o poder de dissipação dos efeitos deste projeto. Através da conscientização, é possível tentar elucidar o fato de que a solução do problema começa com a nossa participação, mudando pequenas atitudes nas nossas vidas e não esperando que a mudança ocorra apenas nas grandes indústrias. Se precisamos repensar valores, este é o momento de revermos atitudes.

\section{Agradecimentos}

À Secretaria de Educação do Estado do Rio de Janeiro (SEEDUC-RJ), e à direção do Colégio Estadual Cizínio Soares Pinto, pelo suporte na realização deste projeto. E a todos os professores e alunos que contribuíram, direta ou indiretamente, para tentar tornar nosso mundo um pouco melhor.

\section{Referências}

ARNEY, K. Vírus: seu papel extraordinário na formação da evolução humana. Science Focus. 19 de março de 2020 às 16:13 https://www.sciencefocus.com/the-human-body/virus-human-evolution/

Acessado em 14 jun. 2020

DESSEN, M.A.; POLONIA, A.C. A família e a escola como contextos de desenvolvimento humano. Paidéia (Ribeirão Preto), Ribeirão Preto, v. 17, n. 36, p. 21-32, Apr. 2007.

FONSECA, A.F.Q. Ambiente e saúde: visão de profissionais da saúde da família. Ambiente. soc. São Paulo, v. 15, n. 2, p. 133-150, agosto de 2012.

HEINBERG, R. Peak Everything: Waking Up to the Century of Declines, New Society Publishers, Gabriola Island, BC, Canada. 2007.

JACOBI, P. R., GUERRA, A. F. S.; SULAIMAN, S. N. e NEPOMUCENO, T.. Mudanças climáticas globais: a resposta da educação. Rev. Bras. Educ., Rio de Janeiro, v. 16, n. 46, p. 135-148, Apr. 2011.

LEITE, S.A.S. A escola e a formação da cidadania ou para além de uma concepção reprodutivista. Psicol. cienc. prof., Brasília, v.9, n.3, p.17-19, 1989.

MAIA, B.R.; DIAS, P.C. Ansiedade, depressão epressão estresse em estudantes universitários: o impacto do COVID-19. Estud. psicol. (Campinas), Campinas, v. 37, e200067, 2020.

MCDONALD, RI, BEATLEY, T. \& ELMQVIST, T. A alma verde da selva de concreto: o século urbano, a penalidade psicológica urbana e o papel da natureza. Sustain Earth, v.1, n.3, 2018.

OLIVEIRA, L.; NEIMAN, Z. Educação Ambiental no Âmbito Escolar: Análise do Processo de Elaboração e Aprovação da Base Nacional Comum Curricular 
(BNCC). Revista Brasileira de Educação Ambiental (RevBEA), v. 15, n. 3, p. 36-52, 21 maio 2020.

OLIVEIRA, T. M. R. DE; AMARAL, C. L. C. Ações para Minimizar a Fragmentação da Educação Ambiental em uma Escola Pública Paulista. Revista Brasileira de Educação Ambiental (RevBEA), v. 15, n. 3, p. 297-314, 27 maio 2020.

PESSANHA, I. R. DE A.; RODRIGUES, D. C. G. DE A.; ALVES, M. P. Materialidade histórica, Educação Ambiental e cidadania: bases para a sustentabilidade ambiental. Revista Brasileira de Educação Ambiental (RevBEA), v. 11, n. 2, p. 216-239, 20 jun. 2016.

PIGNATTI, M. G. Saúde e ambiente: as doenças emergentes no Brasil Ambiente \& Sociedade - Vol. VI I nº. 1 jan./jun. 2003.

RODRIGUES, Ricardo Moreira. Solidão, um fator de risco. Rev Port Med Geral Fam [Internet]. 34(5): 334-338, 2018.

SOUSA, R. N. S. Educação Ambiental: um olhar interior durante a pandemia do coronavirus 19 maio 2020. Destaque, Notícia, Disponível em: $<$ https://www.sema.ma.gov.br/educacao-ambiental-um-olhar-interior-durante-apandemia-do-coronavirus/>, Acessado em 14 jun, 2020.

SOUZA, F. R. DA S. Educação Ambiental e sustentabilidade: uma intervenção emergente na escola. Revista Brasileira de Educação Ambiental (RevBEA), v. 15, n. 3, p. 115-121, 22 maio 2020.

UFJF. NOTÍCIAS. Pandemia e Meio Ambiente: Impactos momentâneos ou nova normalidade? Pesquisa E Inovação. 24 de abril de 2020, Disponível: $<$ https://www2.ufjf.br/noticias/2020/04/24/pandemia-e-meio-ambiente-impactosmomentaneos-ou-nova-normalidade/> Acesso em 14 jun. 2020

\section{Sites:}

Footprint Calculator. Disponível em:

$<$ http://www.footprintnetwork.org/en/index.php/GFN/page/calculators/> Acesso em 21 mar. 2020

WWF. Disponível em:<https://www.wwf.org.br/natureza brasileira/especiais/pegada ecologica/hi storico/> Acesso em 14 jun. 2020 


\section{APÊNDICE I}

\section{Questões e opções de respostas da Pegada Ecológica Adaptada aplicadas no Colégio Estadual Cizínio Soares Pinto, em Niterói, RJ.}

1. Você come carne vermelha:

a) Nunca.

b) Uma a três porções por semana.

c) Quatro a sete porções por semana.

d) Uma porção por refeição.

e) Duas ou mais porções por refeição.

2. Você come peixe?

a) Nunca.

b) Uma a três porções por semana.

c) Quatro a sete porções por semana.

d) Uma porção por refeição.

e) Duas ou mais porções por refeição

3. Consome leite, derivados do leite e ovos com que frequência?

a) Nunca.

b) Uma a três porções por semana.

c) Quatro a sete porções por semana.

d) Uma porção por refeição.

e) Duas ou mais porções por refeição.

4. Você desperdiça alimentos (joga resto de comida fora):
a) Nunca.
b) Raramente.
c) Uma vez na semana.
d) Uma vez ao dia.
e) Toda refeição.

5. Destinação do lixo reciclável em sua casa:

a) Separo o lixo reciclável, o lixo eletrônico e o óleo de cozinha.

b) Separo lixo reciclável e pilhas e baterias.

c) Separo lixo reciclável do orgânico.

d) Não separo lixo porque não existe coleta seletiva onde moro.

e) Não separo o lixo reciclável.
11. Qual meio de transporte você mais utiliza para ir para a escola:
a) Ando a pé.
b) Bicicleta.
c) Ônibus.
d) Transporte Escolar.
e) Carro.

12. Qual é a distância média percorrida por você no trajeto de ida e volta da sua casa à escola em carro ou ônibus?
a) nunca ando de carro ou ônibus
b) 1 a $10 \mathrm{~km}$
c) 10 a $20 \mathrm{~km}$
d) 20 a $30 \mathrm{~km}$
e) 30 a $40 \mathrm{~km}$

13. Com que frequência você troca de celular:
a) Nunca, só troco quando quebra.
b) Uma vez a cada dois anos.
c) Uma vez ao ano
d) Duas ou três vezes ao ano.
e) Sempre, pois procuro estar com o último lançamento

14. Dos alimentos que você consome:

a) Alguns são colhidos da horta de casa.

b) Todos são comprados em feiras.

c) A maioria é comprado na feira e a minoria no mercado.

d) A maioria é comprada no mercado e a minoria na feira.

e) Todos são comprados em mercados

15. Com que frequência você compra roupas e sapatos?

a) Só compro quando posso.

b) Só quando preciso.

c) Uma vez ao ano.

d) Duas ou três vezes ao ano.

e) Sempre, pois procuro estar com os últimos lançamentos. 
6. Quanto de lixo seco (reciclável) você produz em sua casa em um dia:
a) Uma sacola média.
b) Duas sacolas médias.
c) Três sacolas médias.
d) Quatro sacolas médias.
e) Cinco ou mais sacolas médias.

7. Há lâmpadas econômicas (fluorescentes) na sua casa:
a) Todas.
b) Metade.
c) $1 / 4$.
d) Nenhuma.
e) Não sei.

8. Qual o destino do lixo orgânico em sua casa:
a) jogo direto na caçamba de lixo da CLIN*
b) coloco em sacos plásticos e jogo na caçamba de lixo da CLIN
c) jogo em terreno baldio (vazio)
d) jogo na rua
e) jogo na encosta

9. Quanto tempo você fica em frente à TV por dia:
a) Até 30 minutos.
b) De 30 a 60 minutos.
c) De 1 hora a 2 horas.
d) De 2 a 4 horas.
e) Mais de 4 horas.

10.Quanto tempo você usa o computador por dia:
a) Até 30 minutos.
b) De 30 a 60 minutos.
c) De 1 hora a 2 horas.
d) De 2 a 4 horas.
e) Mais de 4 horas.

16. Penso que os passarinhos...

a) Devem viver livres na natureza

b) Podem servir de alimento aos humanos

c) Podem ser engaiolados

d) Podem ser mortos por diversão

e) Mesmo em extinção podem ser fonte de renda

17. Quanto tempo você leva tomando banho:

a) Até 5 minutos.

b) De 5 a 10 minutos.

c) De 10 a 15 minutos.

d) De 15 a 20 minutos.

e) Mais de 20 minutos

18. Que porcentagem de energia elétrica que você usa provém de recursos renováveis?
a) $100 \%$
b) $75 \%$.
c) $50 \%$.
d) $25 \%$.
e) $0 \%$.

19. Quantas pessoas moram na sua casa?
a) duas
b) três a quatro
c) cinco a seis
d) sete
e) mais de sete

20. Quanto ao uso de papel do seu caderno... a) uso o mesmo papel quando erro e utilizo o verso da folha

b) uso o mesmo papel quando erro mas não utilizo o verso da folha c) arranco a folha quando erro e uso como rascunho

d) amasso o papel quando erro e jogo no lixo e) amasso o papel quando erro e jogo no chão 